\title{
Reduction of UV-induced Skin Tumours in Hairless Mice by Topical Non-Steroidal Anti-inflammatory Drugs
}

\author{
Suong N. T. Ngo ${ }^{1,2^{\star}}$ \\ ${ }^{1}$ School of Animal and Veterinary Sciences, The University of Adelaide, Roseworthy, SA 5371, \\ Australia. \\ ${ }^{2}$ School of Pharmacy and Medical Sciences, University of South Australia, Adelaide, SA 5000, \\ Australia.
}

Author's contribution

The sole author designed, analyzed and interpreted and prepared the manuscript.

Article Information

DOI: $10.9734 / \mathrm{JCTI} / 2018 / 39590$ Editor(s):

(1) Saritha Sandra D'souza, University of Wisconsin, Madison, USA

Reviewers:

(1) Umit Tursen, Mersin University, Turkey. (2) Ronald Bartzatt, University of Nebraska, USA. Complete Peer review History: http://www.sciencedomain.org/review-history/23255

Short Research Article

Received $23^{\text {rd }}$ November 2017

Accepted $12^{\text {th }}$ February 2018

Published $20^{\text {th }}$ February 2018

\begin{abstract}
Aims: Inhibition of ultraviolet-A and -B (UVA+B) skin tumour formation by topical treatment with non-steroidal anti-inflammatory drugs (NSAIDs) was investigated in SKH-1 hairless mice.

Methodology: A UV skin tumour study was designed. Group of mice were irradiated with daily doses of UVA+B for approximately 10 min per day, 5 days per week for 10 weeks. After this $10-$ week, there was no further UV-exposure. The integrated UV-A irradiance $(280-320 \mathrm{~nm})$ was $2.4 \mathrm{X}$ $10^{-4} \mathrm{~W} / \mathrm{cm}^{2}$ and the UV-B irradiance $(320-400 \mathrm{~nm})$ was $1.8 \times 10^{-3} \mathrm{~W} / \mathrm{cm}^{2}$. Mice were divided into 4 groups ( $\mathrm{n}=20$ per group). Group 1 was treated with methanol; Group 2 received $2 \%$ indomethacin in methanol; Group 3 received 2\% paracetamol in methanol; Group 4 received 2\% flurbiprofen in methanol. All groups received their treatment once a day, five days per week for 25 weeks. Mice were euthanized after 35 weeks.

Results: The test NSAIDs in methanol were effective in reducing the incidence and size of the skin tumours induced by UVA+B, with a significantly lower average number and/or area of skin tumours observed in the NSAID-treated mice compared to the methanol control animals $(P<$ .05).
\end{abstract}


Conclusion: The results support the hypothesis that topically applied indomethacin, paracetamol, and flurbiprofen can provide protection against skin cancer, even when applied well after the skin has been exposed to the damaging effects of UV-light.

Keywords: Chemoprevention; UV-induced skin tumour; non-melanoma; NSAIDs; topical formulations; skin cancer.

\section{INTRODUCTION}

Skin cancer is the most common type of cancer for males and females in the white population [1]. Among the various malignant skin cancer types, non-melanoma skin cancer (NMSC), including basal cell carcinoma (BCC) and squamous cell carcinoma (SCC) is most common, and is a source of significant morbidity. Basal cell carcinoma represents about $80 \%$ of all reported skin cancers, while squamous cell carcinoma is about $16 \%$, and melanomas represent about $4 \%$ $[1,2]$. Most NMSC occurs in people over 40 years of age, and incidence rates in Australia are believed to be the highest in the world [3]. A 2fold increase in NMSC incidence has also been seen in the United States from 1994 to 2006 [4]. People with light complexions, fair or red hair and who tend to burn easily on exposure to the sun (Fitzpatrick skin grades 1 and 2) are more prone to develop NMSC than those with dark-skin, and males appear to be at higher risk [3].

Once treated for a NMSC, the risk of developing a new NMSC is highest in the subsequent year [3]. From an early review of 7 studies, it has been established that the 3-year cumulative risk for a subsequent NMSC is on average $44 \%$ [5]. There is also a strong association between the risk of developing a subsequent skin cancer and the number of prior skin tumours - that is, the more prior skin cancers, the higher the risk. In one study, the risk was increased from $38 \%$ for patients with fewer than 3 previous NMSC to $93 \%$ for patients with 3 to 9 previous NMSC [6]. Healthcare costs associated with the treatment of skin cancers are over 500 million annually in the United States alone, and it has been estimated that at current rates, 1 in 5 Americans will develop a skin cancer of some sort during their lifetime $[7,8]$. Clearly skin cancer is a major worldwide health problem and is a very costly disease to treat and manage.

There is a causal relationship between excessive exposure to solar ultraviolet (UV) radiation and incidence of skin cancers [3,9]. UV light has been reported as being the main aetiology of NMSC due to DNA damages, such as the creation of clyclobutane dimers and nucleotide mutations [9]. Moreover, p53-gene mutations resulted from UV light could inactivate the p53-gene's ability to inhibit tumor promotions in mutated cells [10]. Preventive methods for NMSC include standard sun protection behaviours, such as applying sunscreen creams with high SPF (sun protection factor), avoiding UV peak hours or periods, and minimising exposure to UV light with protective clothing. As total avoidance of sun exposure would seem unrealistic, other interventions to prevent NMSC are needed. This is greatly beneficial for patients with precursor lesions such as Actinic keratosis, as chemoprevention may inhibit the development of the condition into malignancy [11].

Earlier studies have shown that non-steroid antiinflammatory drugs (NSAIDs) have a potential role in cancer prevention, including NMSC [1215] by inhibition of cyclooxygenase enzymes COX-1 and COX-2, which are involved in carcinogenesis [16]. Chemically, NSAIDs are divided into a number of subclasses. They include the salicylic acid derivatives - e.g. aspirin, the indole and indene acetic acids - e.g. indomethacin, the heteroaryl acetic acids - e.g. diclofenac, and the arylpropionic acid derivatives - e.g. flurbiprofen [17]. Paracetamol is considered as an atypical NSAID as it is a week inhibitor of COXs. Several studies have reported that COX-2 is up-regulated in many forms of cancer, including human colorectal adenocarcinoma, breast, cervical, prostate, lung and skin tumours [18,19], and have indicated a relationship between the NSAID antiproliferative effect and COX inhibition [20-23]. Several lines of evidence also suggested that antiproliferative effects of NSAIDs are mediated via mechanisms that are at least partly independent of COX inhibition [22,24-27]. The role of COX inhibition in NSAID antiproliferative effect is presently unclear. Recently, a study by Sørensen also reported that the use of NSAID, including non-selective NSAIDs, overall reduced the risk of certain types of skin cancer [28].

To test the relative effectiveness of NSAIDs as anticancer agents, a UV skin tumour study in 
hairless mice was designed. It was found that topical NSAIDs from 3 subclasses; indomethacin, flurbiprofen, and paracetamol can provide protection against skin cancer even when applied well after the skin has been exposed to the damaging effects of UV-light. The results of the tumor study and the effects of the three test NSAIDs, including indomethacin, flurbiprofen, and paracetamol that has a weak COX inhibition action are presented in this paper.

\section{MATERIALS AND METHODS}

\subsection{Chemicals and Reagents}

Indomethacin, paracetamol, and flurbiprofen were obtained from the Sigma Chemical Company (Castle Hill, NSW, Australia). Methanol and other chemicals were purchased from Biolab (Clayton, VIC, Australia). All other chemicals were purchased commercially and were of analytical grade.

\subsection{Mice}

All animals received human care according to the "Australian code for the care and use of animals for scientific purposes" (National Health and Medical Research Council, NHMRC, AE-16 $7^{\text {th }}$ Edition 2004). The Animal Ethics Committee at The University of South Australia approved the study protocols for all animal experiments.

Female SKH-1 mice were obtained from the Animal Resource Centre (Perth, Western Australia) at four weeks of age. Animals were randomly allocated to one of four treatment groups and allowed free access to a standard diet formulated according to the American Institute of Nutrition (AIN-89 diet, Glen Forrest Feeds, Perth, WA. Australia). The animals were acclimatized and caged together in groups of 10 mice. The mice were maintained under standard conditions of a $12 \mathrm{~h}$ dark $/ 12 \mathrm{~h}$ light cycle, at the temperature of $24 \pm 2^{\circ} \mathrm{C}$, and relative humidity of $50 \pm 10 \%$.

\subsection{UV Source}

A purpose-built apparatus was used for UV irradiation. The UV emission was produced by 6 UV-A lamps (model 40BL, Sylvania) symmetrically housed around a single UV-B lamp (model FL40SE, Philips). The spectrum was measured with a spectroradiometer (model IL 1700, International Light, Newburyport, MA). The integrated UV-A irradiance (280-320 nm) was 2.4 $\times 10^{-4} \mathrm{~W} / \mathrm{cm}^{2}$ and the UV-B irradiance $(320-400$ $\mathrm{nm}$ ) was $1.8 \times 10^{-3} \mathrm{~W} / \mathrm{cm}^{2}$.

\subsection{Irradiation of Mice}

After one week of acclimatization, animals in all groups were exposed to UVA+B approximating solar UV emission as described above. Irradiation was commenced at $5 \mathrm{~min} /$ day and increased to a maximum of $10 \mathrm{~min} /$ day. Animals showing undue reddening of the skin (i.e., $>2$ minimal erythematous dose) were not irradiated further until the erythema had disappeared. Differences between cumulative doses did not exceed $1 \%$ of the total UV exposure. No mice exhibited any evidence of blister formation or skin peeling. Mice were irradiated once daily, 5 days per week for 10 weeks. After this 10-week irradiation, there was no further UV exposure.

\subsection{Tumor Study}

Mice in all groups ( $n=20$ per group) were irradiated daily for 10 weeks with UVA+B as described above. After exposure to UV for 10 weeks, mice were painted dorsally with (Group 1) $70 \%$ methanol, (Group 2) $2 \%$ indomethacin in $70 \%$ methanol, (Group 3) $2 \%$ paracetamol in $70 \%$ methanol, (Group 4) 2\% flurbiprofen in $70 \%$ methanol. The selection of the dose of $2 \%$ of topical NSAID was based on preliminary experiments testing a range of concentrations of NSAIDs (from $0.5 \%$ up to $3 \%$ ) on a small number of animals.

All groups received their treatment once a day, five days per week for 25 weeks. Animals were monitored daily for their appearance, and as papillomas or tumours appeared, they were counted and measured regularly. After 35 weeks, the experiment was ended, and all the mice were euthanized with a lethal dose of pentobarbital sodium (Nembutal).

\subsection{Statistical Analysis}

Statistical analysis was performed using Microsoft Excel software. Tumour multiplicity and total tumor area were compared between the control group and the NSAID treated groups. Tumor multiplicity, expressed as the mean number of tumours, the mean number of tumours plus papillomas per animal, and the total affected area were analysed by Student's $t$ test. A $P$ value $<.05$ was considered to be significant. Data concerning the tumor area were 
transformed using the square root of the area, prior to performing the Student's $t$ test. Data are presented as mean \pm SD of total animals/group.

\section{RESULTS}

\subsection{Mice Survival}

The majority of the mice survived the full 35week study (see Table 1). The deaths were higher in two of drug treatment groups than the placebo. A number of mice in the indomethacin group did not survive the entire experimental period and died due to noticeable NSAID's toxicity, such as GI disturbance, bleeding which may be possibly resulted from systemic absorption of indomethacin. Two mice in the flurbiprofen group died in week 30 and 31 of the study. No drug toxicity or other causes of death were observed for other groups.

\subsection{Evaluation of Chemopreventive Effects}

The incidence of tumours, the mean number of tumours and mean number of tumours plus papillomas, and the total areas found in the various groups at the end of the 35-week study are summarized in Table 2. No tumours or papillomas were present in mice during the 10 weeks of UV exposure. Data are presented as tumours, and tumours plus papillomas as the natural progression of UVA+B-induced skin cancer is from the initiated cell to a benign papilloma to cancer (defined as an invasive lesion) and in some cases the distinction could not be made unequivocally.

The incidence of UVA+B-induced skin tumours was reduced in the groups treated with paracetamol and indomethacin, to about twothirds and four-fifths that of the methanol only group, respectively. The mean number of tumours was reduced in the NSAID treated groups and was statistically significant for paracetamol $(P<.05)$, but not for indomethacin and flubiprofen possibly due to the large standard errors. The mean number of tumours plus papillomas was also lower and was statistically significant for indomethacin and paracetamol $(P<.05)$, not for flurbiprofen.

The mean area of the tumours and the mean area of tumours plus papillomas were also calculated as an index of tumour burden on the mice. Both the mean area of tumours (see Table 2 ) and the mean area of tumours plus papillomas were significantly reduced in mice treated with indomethacin and flurbiprofen than that in methanol control animals $(P<.05)$; but were not statistically significant for paracetamol. The mean area of tumours plus papillomas is presented in Fig. 1.

Table 1. Number of surviving mice in each group during 25 weeks of topical treatment with $2 \%$ indomethacin, or $2 \%$ paracetamol, or $2 \%$ flurbiprofen $^{a}$

\begin{tabular}{|c|c|c|c|c|c|c|c|c|c|c|c|c|}
\hline Week number & 24 & 25 & 26 & 27 & 28 & 29 & 30 & 31 & 32 & 33 & 34 & 35 \\
\hline Placebo & 20 & 20 & 20 & 20 & 20 & 20 & 20 & 20 & 20 & 20 & 19 & 19 \\
\hline Paracetamol & 20 & 20 & 20 & 20 & 20 & 20 & 20 & 20 & 20 & 20 & 20 & 20 \\
\hline Flurbiprofen & 20 & 20 & 20 & 20 & 20 & 20 & 19 & 18 & 18 & 18 & 18 & 18 \\
\hline Indomethacin & 20 & 20 & 19 & 19 & 18 & 17 & 15 & 15 & 15 & 15 & 15 & 15 \\
\hline
\end{tabular}

Table 2. Tumor multiplicity and burden in mice receiving topical treatment with $2 \%$ indomethacin, paracetamol, or flurbiprofen after 10-week UV-A + B exposure ${ }^{a}$

\begin{tabular}{|c|c|c|c|c|c|}
\hline & \multirow[t]{2}{*}{ Survival } & \multirow{2}{*}{$\begin{array}{l}\text { Percentage of surviving } \\
\text { mice with tumours }\end{array}$} & \multicolumn{2}{|c|}{ Tumours $^{\mathrm{b}}$} & \multirow{2}{*}{$\begin{array}{l}\text { Tumours \& } \\
\text { Papillomas }\end{array}$} \\
\hline & & & Number & Area $\left(\mathrm{mm}^{2}\right)$ & \\
\hline Methanol & 19 & $68 \%$ & $1.53 \pm 0.96$ & $14.68 \pm 11.24$ & $1.76 \pm 0.83$ \\
\hline Indomethacin & 15 & $53 \%$ & $0.66 \pm 0.51$ & $1.1 \pm 0.48^{\star}$ & $1.16 \pm 0.40$ \\
\hline Paracetamol & 20 & $45 \%$ & $1.00 \pm 0.57^{*}$ & $3.41 \pm 4.00$ & $1.28 \pm 0.48$ \\
\hline Flurbiprofen & 18 & $61 \%$ & $0.88 \pm 0.60$ & $5.27 \pm 4.19^{x}$ & $1.55 \pm 0.78$ \\
\hline
\end{tabular}




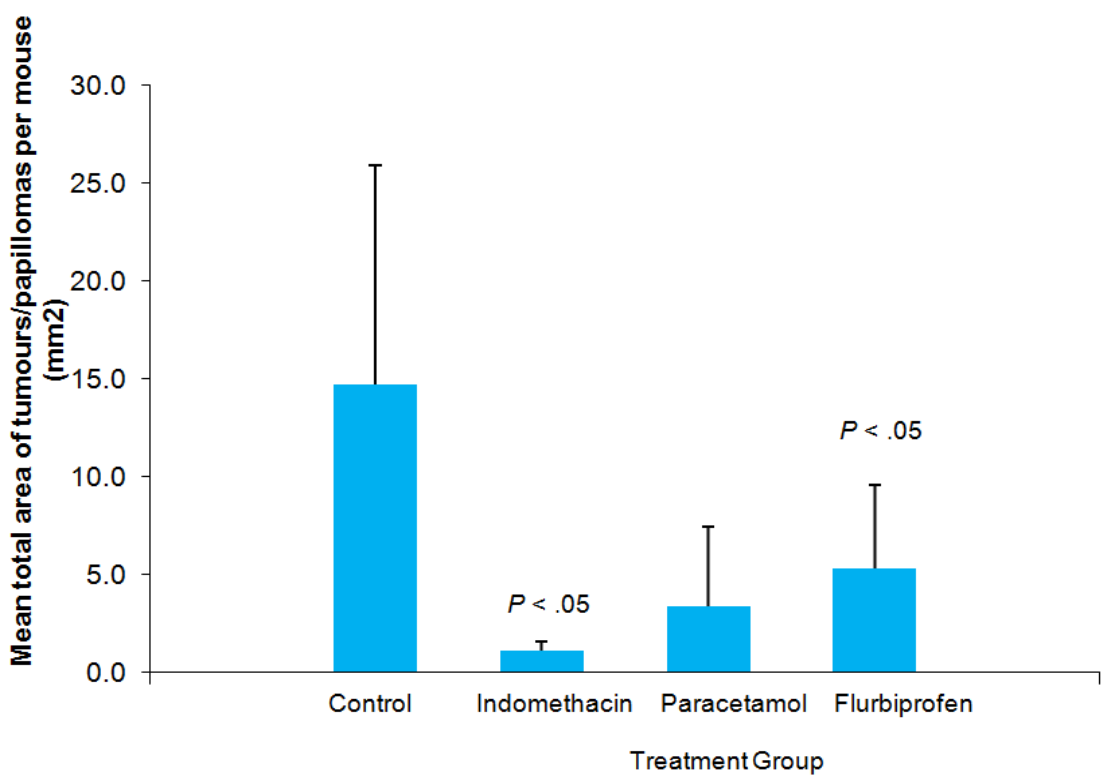

Fig. 1. The mean total area of tumours and papillomas per mouse in the NSAID treated groups compared to the placebo at the end of the study

Data are presented as mean $\pm S D$ of total animals/group

\section{DISCUSSION}

In this study, inhibition of UVA+B-induced skin tumour formation by 3 test NSAIDs from different subclasses; indomethacin, flurbiprofen, and paracetamol adds further support to the hypothesis that NSAIDs can provide protection against skin cancer, even when applied well after the skin has been exposed to the damaging effects of UV-light. This finding is particularly significant given the latency period of skin cancer in humans.

The chemopreventive treatments with systemic NSAIDs, including aspirin, ibuprofen, indomethacin and paracetamol have previously been shown to reduce the risk of developing NMSC [12-14,29]. Previous human populationbased case-control studies demonstrated a reduced risk of having NMSC in ibuprofen $[12,13]$, indomethacin [12], paracetamol [13] and aspirin users [13]. Lower risk of NMSC with paracetamol use has also been found in previous human prospective study, with a reduced risk associated with a higher frequency of use $(P=$ .04) [29]. An RCT in 1402 AK (actinic keratosis) patients resulted in a reduction in the risk of developing NMSC for aspirin treatment [14]. It has earlier been shown that orally administered NSAID indomethacin [30] and celecoxib could inhibit development of UVB induced skin tumours in mice [30-33] and in human RCT [34]. Unfortunately, because of the toxicity of indomethacin due to systematic absorption, it was not possible to study its effects at higher concentrations. Regarding the use of topical NSAIDs, only one earlier study has shown a delayed onset and reduced development of skin tumours in mice using celecoxib combined with zileuton, a 5-lipoxygenase inhibitor [35]. In the present study, topical indomethacin was shown to have the greatest protective effects compared to paracetamol and flurbiprofen. However, it was also associated with a lower survival of mice, which was consistent with that reported in the literature. Overall, 3 test compounds, including week COX inhibitor paracetamol, were effective in reducing the mean number and/or area of skin tumours in hairless mice that had been exposed to UVA+B light only during earlier stages of their life (before drug treatment was commenced). The results of this study further support the potential use of NSAIDs as skin cancer chemo-preventive agents.

\section{CONCLUSION}

The results support the hypothesis that topically applied indomethacin, paracetamol, and flurbiprofen can provide protection against skin cancer, even when applied well after the skin has been exposed to the damaging effects of UV- 
light. As topical administration of drugs would lead to less side effects compared with systemic administration, the idea of topical NSAID to prevent UV-induced NMSC with minimal cardiovascular complications and gastrointestinal bleeding is worth being further investigated.

\section{CONSENT}

It is not applicable.

\section{ETHICAL APPROVAL}

As per international standard or university standard, written approval of Ethics committee has been collected and preserved by the author(s).

\section{COMPETING INTERESTS}

Author has declared that no competing interests exist.

\section{REFERENCES}

1. Guy GP, Ekwueme DU. Years of potential life lost and indirect costs of melanoma and nonmelanoma skin cancer: A systematic review of the literature. Pharmato Economics. 2011;29(10):863874.

2. Trakatelli $\mathrm{M}$, Ulrich $\mathrm{C}$, delMarmol $\mathrm{V}$, Euvrard S, Stockfleth E, Abeni D. Epidemiology of non-melanoma skin cancer (NMSC) in Europe: Accurate and compa- rable data are needed for effective public health monitoring and interventions. Br J Dermatol. 2007;156(Suppl):1-7.

3. Diepgen TL, Mahler V. The epidemiology of skin cancer. $\mathrm{Br} J$ Dermatol. 2002;146(61)(Suppl):1-6.

4. Rogers HW, Weinstock MA, Harris AR, Hinckley MR, Feldman SR, Fleischer AB, Coldiron BM. Incidence estimate of nonmelanoma skin cancer in theUnited States, 2006. Arch Dermatol. 2010;146(3):283-287.

5. Marcil I, Stern RS. Risk of developing a subsequent nonmelanoma skin cancer in patients with a history of nonmelanoma skin cancer. Arch Dermatol. 2000;136:1524-1530.

6. Czarnecki D, Mar A, Staples M, Giles G, Meehan CL. The development of nonmelanocytic skin cancer in people with a history of skin cancer. Dermatology. 1994; 184:364-367.

7. Stern RS. Prevalence of a history of skin cancer in 2007: results of an incidencebased model. Arch Dermatol. 2010;146(3):279-282.

8. Rigel DS. Photoprotection: A 21st century perspective. Br J Dermatol. 2002;146(61) (Suppl):34-37.

9. Brash DE. Sunlight and the onset of skin cancer. Trends Genet. 1997;13(10):410414.

10. Brash DE, Rudolph JA, Simon JA, Lin A, McKenna GJ, Baden HP, Halperin AJ, Pontén J. A role for sunlight in skin cancer: UV-induced p53 mutations in squamous cell carcinoma. Proc Natl Acad Sci USA. 1991;88(22):10124-10128.

11. Salasche SJ. Epidemiology of actinic keratoses and squamous cell carcinoma. J Am Acad Dermatol. 2000;42(Suppl):4-7.

12. Johannesdottir SA, Chang ET, Mehnert F, Schmidt $M$, Olesen AB, Sørensen HT. Nonsteroidal anti-inflammatory drugs and the risk of skin cancer: a population-based case-control study. Cancer. 2012;118(19): 4768-4776.

13. Torti DC, Christensen BC, Storm CA, Joan F, Ann EP, Michael SZ, et al. Analgesic and nonsteroidal anti-inflammatory use in relation to nonmelanoma skin cancer: A population-based case-control study. J Am Acad Dermatol. 2011;65(2):304-312.

14. Clouser MC, Roe DJ, Foote JA, Harris RB. Effect of non-steroidal anti-inflammatory drugs on non-melanoma skin cancer incidence in the KICAP-AK trial. Pharmacoepidemiol Drug Saf. 2009;18(4): 276-283.

15. Asgari M, Emily W, Chren M. Nonsteroidal anti-inflammatory drug use in the prevention and treatment of squamous cell carcinoma. Dermatol. Surg. 2004;30:13351342.

16. Baron JA. Epidemiology of non-steroidal anti-inflammatory drugs and cancer. Prog. Exp. Tumor Res. 2003;37:1-24.

17. Hardman JG, Limbird LE Eds. Goodman \& Gilman's the pharmacological basis of therapeutics. McGraw Hill Publishers, New York, USA; 1996.

18. Chun KS, Surh YJ. Signal transduction pathways regulating cyclooxygenase-2 expression: Potential molecular targets for chemoprevention. Biochem. Pharmacol. 2004;68:1089-1100. 
19. Fischer SM, Pavone A, Mikulec C, Langenbach $R$, Rundhaug JE. Cyclooxygenase-2 expression is critical for chronic UV-induced murine skin carcinogenesis. Mol. Carcinog. 2007;46:363-371.

20. Taketo M. Cyclooxygenase-2 inhibitors in tumourigensis (Part II). J. Natl. Cancer Inst. 1998;90:1609-1620.

21. Oshima $M$, Dinchuk JE, Kargman SL, Oshima H, Hancock B, Kwong $E$, et al. Suppression of intestinal polyposis in APC716 knockout mice by inhibition of cyclooxygenase 2 (COX-2). Cell. 1996;87:803-809.

22. Elder D, Halton D, Hague A, Paraskeva C. Induction of apoptotic cell death by a cyclooxygenase-2 (COX-2)-selective nonsteroidal antiinflammatory drug: Independence from COX-2 protein expression. Clin. Cancer Res. 1997;3:1679-1683.

23. Rigas $B$, Shiff SJ. Is inhibition of cyclooxygenase required for the chemopreventive effect of NSAIDs in colon cancer? A model reconciling the current contradiction. Med. Hypothesis. 2000;54:210-215.

24. Thompson $H$, Jiang $C$, Lu J, Mehta RG, Piazza GA, et al. Sulfone metabolite of sulindac inhibits mammary carcinogenesis. Cancer Res. 1997;57:267-271.

25. Wechter W, Kantoci D, Murray ED Jr, Quiggle DD, Leipold DD, Gibson KM, et al. R-Flurbiprofen chemoprevention and treatment of intestinal adenomas in the APCMin/+ mouse model: Implications for prophylaxis and treatment of colon cancer. Cancer Res. 1997;57:4316-4324.

26. Hanif $R$, Pittas A, Feng $Y$, Koutsos MI, Qiao L, Staiano-Coico L, et al. Effects of nonsteroidal anti-inflammatory drugs on proliferation and on induction of apoptosis in colon cancer cells by a prostaglandinindependent pathway. Biochem. Pharmacol. 1996;52:237-245.

27. Liu G, Ma W, Bode AM, Zhang Y, Dong Z. NS-398 and proxicam suppress UVBinduced activator protein 1 activity by mechanisms independent of cyclooxygenase 2. J. Biol. Chem. 2003;278:2124-2130.

28. Sørensen HT. Nonsteroidal antiinflammatory drugs and the risk of skin cancer. Cancer. 2012;118:4768-4776.

29. Jeter JM, Han J, Martinez ME, Alberts DS, Qureshi AA, Feskanich D. Non-steroidal anti-inflammatory drugs, acetaminophen, and risk of skin cancer in the Nurses' Health Study. Cancer Causes Control. 2012;23(9):1451-1461.

30. Fischer S, Lo HH, Gordon GB, Seibert K, Kelloff G, Lubet RA, et al. Chemopreventive activity of celecoxib, a specific cyclooxygenase-2 inhibitor, and indomethacin against ultraviolet-induced skin carcinogenesis. Mol Carcinog. 1999;25:231-240.

31. Wilgus TA, Koki AT, Zweifel BS, Kusewitt DF, Rubal PA, Oberyszyn TM. Inhibition of cutaneous ultraviolet light B-mediated inflammation and tumor formation with topical celecoxib treatment. Mol Carcinog 2003;38:49-58.

32. Orengo IF, Gerguis J, Phillips R, Guevara A, Lewis AT, Black HS. Celecoxib, a cyclooxygenase 2 inhibitor as potential chemopreventive to UV-induced skin cancer: a study in the hairless mouse model. Arch Dermatol. 2002;138:751-755.

33. Fischer SM, Conti CJ, Viner J, Aldaz CM, Lubet RA. Celecoxib and difluoromethylornithine in combination have strong therapeutic activity against UV-induced skin tumors in mice. Carcinogenesis. 2003;24:945-952.

34. Elmets CA, Viner JL, Pentland AP, Cantrell $W$, Lin $H Y$, Bailey $H$, et al. Chemoprevention of nonmelanoma skin cancer with celecoxib: A randomized, double-blind, placebo-controlled trial. J Natl Cancer Inst. 2010;102(24):1835-1844.

35. Fegn L, Wang Z. Topical chemoprevention of skin cancer in mice, using combined inhibitors of 5-lipoxygenase and cyclooxygenase-2. J Laryngol Otol. 2009;123(8):880-884.

(c) 2018 Ngo; This is an Open Access article distributed under the terms of the Creative Commons Attribution License (http://creativecommons.org/licenses/by/4.0), which permits unrestricted use, distribution, and reproduction in any medium, provided the original work is properly cited.

Peer-review history:

The peer review history for this paper can be accessed here: http://www.sciencedomain.org/review-history/23255 